\title{
Valvular and Supravalvular Aortic Stenosis Secondary to Familial Hyperlipidemia
}

\section{Faruk Akturk* Ahmet Arif Yalçın, Mehmet Ertürk, Fatih Uzun}

Istanbul Mehmet Akif Ersoy Thoracic and Cardiovascular Surgery Training and Research Hospital, Turkey

\section{Case Report}

Familial hypercholesterolemia (FH) is an autosomal dominant disorder characterized by high levels of low density lipoprotein (LDL) and premature coronary artery disease. Mutations in low density lipoprotein (LDL) receptors induce pathologic mechanisms resulting in this disorder. Hypercholesterolemia also affects aortic valve and aortic root together with coronary arteries $[1,2]$. Herein we present a 46 year old female patient with heterogenous familial hyperlipidemia leading to valvular and supravalvular aortic stenosis.

A 46 year old female patient was admitted to the cardiology department with dizziness, dyspnea and chest pain on exertion. On physical examination, arcus cornealis, and extensor tendon xanthomas were observed. Blood pressure was 160/90 in the right arm and 140/70 in the left arm. A carotid bruit was heard over both carotid arteries, louder over the right one. Serum LDL level was $580 \mathrm{mg} / \mathrm{dl}$. Transthoracic echocardiography revealed mild mitral regurgitation, severe aortic stenosis with moderate aortic regurgitation and constriction above coronary sinuses. Transeosaphagial echocardiography and multidetector computed tomography (MDCT) were ordered to evaluate the aortic root and aortic valve. Supravalvular narrowing was seen in both transeosaphageal echocardiography and MDCT (Figures 1 and 2). A coronary angiography was ordered to evaluate coronary anatomy, with routinely used $6 \mathrm{~F}$ JL cathater we could not engage left main coronary artery, so we used 5F JL3 cathater. Similarly we had to use $5 \mathrm{~F}$ JR 3,5 for evaluation of right coronary artery. On coronary angiography nonobstructive coronary artery disease was detected (Figure 3). Medical treatment consisting of intense lipid lowering therapy, beta blocker and acetylsalicilic acid, was begun and the patient was referred to surgery for aortic valve and root replacement. A Benthall procedure with No 21 bileaflet aortic valve replacement was performed. In the course of operation, significant ostial stenosis of left main coronary artery and right coronary artery was also discovered, and aorto coronary bypass grafting was performed. On follow up, the patient is doing well without complaints under the treatment of rosuvastatin $40 \mathrm{mg} /$ day, ezetimibe $10 \mathrm{mg} /$ day and lipid apheresis once in two weeks.

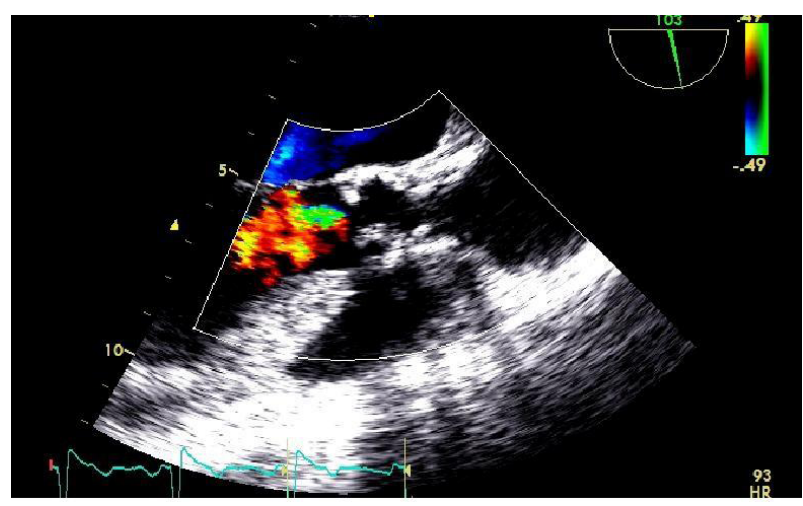

Figure 1: TEE image of valvular and supravalvular aortic stenosis.

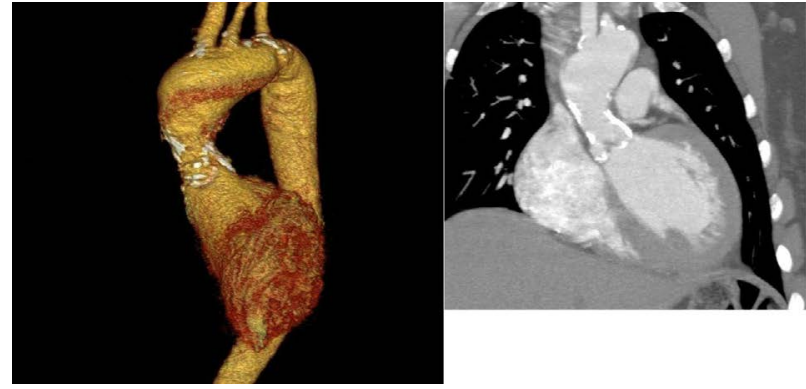

Figure 2: MDCT image of aortic valve and ascending aorta.

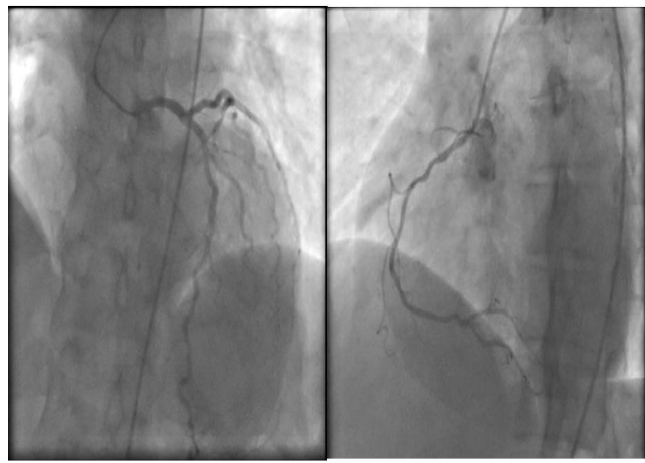

Figure 3: Coronary angiographic images of the patient.

\section{Discussıon}

Atherosclerosis is one of the deleterious consequences of $\mathrm{FH}$. Normally, atheromatous plaquing occurs most severely in the abdominal aorta. However, in $\mathrm{FH}$, there is a reverse phenomenon of atherosclerosis, so that ascending aorta and aortic root is more severely affected than the abdominal aorta and its branches. This issue of fact is responsible for valvular and supravalvular aortic stenosis, rarely seen in patients with $\mathrm{FH}[3]$.

Most patients with familial hypercholesterolemia also suffer from ischemic heart disease. Not suprisingly, atheromatous plaquing of the wall of the aortic root results in ostial stenosis of the coronary

*Corresponding author: Dr. Faruk Akturk, Istanbul Mehmet Akif Ersoy Training and Research Hospital, Turkey, E-mail: farukakturk@gmail.com

Received January 17, 2013; Accepted February 19, 2013; Published February 28,2013

Citation: Akturk F, Yalçın AA, Ertürk M, Uzun F (2013) Valvular and Supravalvula Aortic Stenosis Secondary to Familial Hyperlipidemia. J Cardiovasc Dis Diagn 1 : 102. doi:10.4172/2329-9517.1000102

Copyright: (C) 2013 Akturk F, et al. This is an open-access article distributed under the terms of the Creative Commons Attribution License, which permits unrestricted use, distribution, and reproduction in any medium, provided the original author and source are credited. 
arteries located at the upper part of the sinus of Valsalva. Especially in severe cases, even sudden death may occur at an early age. In such cases autopsy reveals coronary ostial stenosis by atheroma, despite the lack of significant stenosis of the branches of the coronary arteries. In the selective coronary angiography procedure, the contrast medium is injected from the catheter tip at a point when catheter just passed over the ostium, so that it is difficult to disclose the relationship between the ostium of the coronary artery and the atheromatous plaque of the aortic wall [3]. Accordingly, diagnostic angiography had overlooked ostial stenosis in our case as well.

Transthoracic and transeosophageal echocardiography are useful diagnostic modalities for evaluation of ascending aorta and aortic valve [3]. However coronary anatomy cannot be visualized properly by echocardiography. Coronary CT angiography seems to be a better diagnostic tool for ostial evaluation of coronary arteries in this kind of patients like the present case.
In conclusion, hypercholesterolemia, can cause valvular disease even at a young age. Thus, hyperlipidemia, especially when seen in young patients, should be considered as a risk factor for aortic valve and root pathology. Also, aortic valvulopathy necessitates screening for lipid disturbances. Additionally, in evaluation of patients with $\mathrm{FH}$ coronary CT angiography should be the method of choice to diagnose suspected ostial lesions.

\section{References}

1. Marks D, Thorogood M, Neil HA, Humphries SE (2003) A review on the diagnosis, natural history, and treatment of familial hypercholesterolaemia. Atherosclerosis 168: 1-14.

2. Arora G, Fraser CD, Kearney DL, Vincent JA (2006) Severe supravalvar aortic stenosis in familial homozygous hypercholesterolemia. Pediatr Cardiol 27: 282 285.

3. Beppu S, Minura Y, Sakakibara H, Nagata S, Park YD, et al. (1983) Supravalvula aortic stenosis and coronary ostial stenosis in familial hypercholesterolemia: two-dimensional echocardiographic assessment. Circulation 67: 878-884. 